Title of the white paper: The Importance of Venus Experimental Facilities

Primary author's name: Alison R. Santos

Primary author's phone number: 216-433-2674

Primary author's institution: NASA Glenn Research Center

Primary author's email address: alison.r.santos@ nasa.gov

Co-authors with their respective institutions:

Jeffrey Balcerski, Ohio Aerospace Institute

Devon M. Burr, Northern Arizona University

Jorn Helbert, German Aerospace Center

Gary Hunter, NASA Glenn Research Center

Noam Izenberg, John's Hopkins University Applied Physics Lab

Natasha Johnson, NASA Goddard Space Flight Center

Erika Kohler, NASA Goddard Space Flight Center

Tibor Kremic, NASA Glenn Research Center

Sara Port, NASA Glenn Research Center

Co-signers with their respective institutions:

Paul Byrne, $N C S U$

Jamie Cordova, UW-Madison

Darby Dyar, Mt. Holyoke College/PSI

Martha Gilmore, Wesleyan University

Jeffery Hall, $J P L$

Kandis-Lea Jessup, SwRI, Boulder

Jonathan A. Lewis, NASA JSC

Joe O'Rourke, $A S U$

Colby Ostberg, UC Riverside

Sue Smrekar, JPL

Timothy N. Titus, USGS Flagstaff

Constantine Tsang, $S w R I$

Michael Way, NASA GISS

Thomas Widemann, LESIA

Kathleen E. Vander Kaaden, Jacobs-NASA JSC 


\section{The Importance of Venus Experimental Facilities}

Introduction: The planet Venus is the most Earth-like body in terms of its size, composition, and location in the solar system, and hosts some similar geologic processes, such as widespread basaltic volcanism and aeolian sand transport [1,2]. At the same time, Venus offers what is likely the greatest set of technical challenges to exploration out of all terrestrial bodies [3]. With an average surface temperature of $\sim 460{ }^{\circ} \mathrm{C}$ and pressure of $\sim 92$ bars (at mean planetary radius) [4], many types of instrumentation, including conventional electronics, are outside their standard operating conditions on Venus $[5,6]$. On top of these factors, the Venusian atmosphere is a chemically reactive mixture of carbon and sulfur species, including $\mathrm{SO}_{2}, \mathrm{CO}_{2}, \mathrm{H}_{2} \mathrm{~S}$, and $\mathrm{COS}$, in addition to other trace, but important, reactive species such as $\mathrm{HCl}$ and $\mathrm{HF}$ [4, 7]. This dense gas mixture will react with most structural and fabrication materials, aggressively corroding metals, and ruining electrical wiring $[8,9]$.

Nevertheless, the exploration of Venus is vital in our quest to understand the evolution of terrestrial planets, and can reveal why some sustain liquid water, plate tectonics, and a complex biosphere like Earth, while others develop hostile environments. The answers to these questions, along with numerous other vital science questions such as those presented in the VEXAG Scientific Goals, Objectives, and Investigations for Venus Exploration [10], can only be found through exploration of Venus.

Crucial tools in the exploration of Venus are experimental facilities that can replicate the pressure, temperature, and chemical conditions of that world. Such facilities allow us to develop, test, and prove technologies to explore Venus, and understand how to manage the challenges caused by the Venus environment. These facilities also benefit the scientific study of Venus as they can be used as laboratories to investigate the natural processes that occur in this extreme environment. Because these facilities advance both science and technology, they contribute to all parts of the exploration cycle, including investigating environmental phenomena that missions will need to survive and measure, developing and testing of technology and mission hardware to send to Venus, and using laboratory investigations to understand past and future mission data. This capability to contribute to all parts of the Venus exploration cycle makes Venus experimental facilities critical to moving forward our understanding of this planet in the next decade.

Current Capabilities: A "facility" for the purposes of this discussion consists of a chamber or reaction vessel and its accompanying heating system, gas control system, and data collection system. A list of current facilities with Venus capabilities is given in Table 1. A critical advancement in recent years is that the barriers to replication of the Venus environment have been overcome at multiple institutions; this represents a significant advancement in the development of Venus experimental facilities since the last Decadal Survey. Multiple facilities are now capable of replicating the temperature and pressure of the Venus surface. The main variations in most of these facilities are the experimental chamber volumes, and how the gas composition in the replicated environment is treated, both in terms of what species are supplied and how they are monitored.

The listed facilities run the gamut ranging from supporting technology and instrumentation development, mission development, and varied science experimentation. It is important to remember that different investigations require different facility capabilities, thus diversity in capabilities is required. More complex and capable facilities are needed to provide testing for whole mission concepts, while simpler more limited systems can be used to test and develop individual subsystems or technologies, such as functionality of specific instruments or

measurement techniques. Similarly, some scientific investigations may focus on select atmospheric gases, while others require a more complete replication of the atmospheric 
composition of Venus. Therefore, it is important to also keep a balance of different capabilities available to the community. Some types of development and testing require relatively long durations in these facilities (e.g., durations of days or weeks), making replication of capabilities at different facilities a necessity, not a redundancy, in order to efficiently foster advancements in Venus science and technology.

All of these facilities help us work towards the goal of understanding and exploring Venus, and the flexibility provided by the current array of facilities allows many experimental needs to be met. It is important that these capabilities are at the minimum maintained as we push forward to return to Venus, but they must be expanded in order to provide the best opportunities for mission technology development and further scientific discovery.

Applications for Venus Experimental Facilities: Current and past Venus facilities have been valuable research and development tools, resulting in a number of advancements in the areas of science and technology, although much work remains to be done. Within these broad fields are several specific applications of these facilities.

Mission/technology development. The variety of facility formats allow use for many different phases of mission and technology development. Several facilities with smaller chamber volumes have seen use for testing of individual components, sensors, or materials for development of mission hardware. For example, the VICI chamber, the Cassiopeia chamber, and the AVEC chamber have been used to test the stability of various sensors and electrical components at Venus conditions for mission concepts and Small Business Innovation Research (SBIR) partnerships.

Other facilities are uniquely designed to develop specific instruments and measurement techniques for Venus exploration. For example, the Planetary Spectroscopy Laboratory (PSL) at the German Aerospace Center (DLR) has designed a chamber to demonstrate and calibrate NIR spectroscopy for Venus [11-14]. This data can be used as a reference to compare with surface emissivity spectra obtained by a future Venus orbiter. Furthermore, the emissivity chamber has an NIR transparent window allowing mounting of NIR spectrometers built for future Venus orbiter missions to take measurements at Venus conditions, for instrument calibration and performance study. Los Alamos National Laboratory (LANL) has designed a chamber specific for testing LIBS/Raman techniques to adapt them to the Venus environment [15].

Facilities with larger chambers and multiple feedthrough access ports, such as the NASA Glenn Extreme Environments Rig (GEER) facility, are being used to test and develop whole mission concepts, for example, the Long Lived In-Situ Solar System Explorer (LLISSE). This includes making use of electrical feedthroughs for development of ambient Venus electronics and sensors, and eventually using the large chamber size to test a full model of a LLISSE unit [16].

Science investigations. Many science questions can be investigated in these facilities using tailored experiments (see White Paper from Treiman et al.). Many past studies have been conducted on mineral stability and reaction rates, but most of them have used techniques that only replicated a limited set of parameters of the Venus surface environment [e.g., 17-22]. These studies are valuable, as they often can be extrapolated to the true Venus surface conditions, and they provide important baselines in our understanding of Venus weathering processes. Currently, many studies are taking advantage of modern facilities to approach the question of weathering reactions/material stability on the surface of Venus. These include exposing various rocks, glasses, and minerals that may exist on Venus to complex gas mixtures at temperature and pressure conditions resembling different surface elevations on Venus to assess their stability and potential weathering reactions [e.g., 23-26]. This is vital to understanding Venus geochemical processes and interpreting existing Venus data, for example the radar anomalies seen in the highlands. The 
capability of these facilities to use gas mixing at pressure and temperature allows investigations of competing reactions at the Venus surface and the effect different species' concentrations have on

Table 1: Summary of Available Venus Test Facilities

* known in the literature as both the Venus Wind Tunnel [e.g., 27] and the Titan Wind Tunnel [e.g., 28, 29].

\begin{tabular}{|c|c|c|c|c|c|}
\hline Facility & Dimensions & $\begin{array}{c}\text { Max } \\
\text { Pressure } \\
\text { (bar) }\end{array}$ & $\begin{array}{c}\text { Max } \\
\text { Temperature } \\
\left({ }^{\circ} \mathrm{C}\right)\end{array}$ & Gas Species & Notes \\
\hline $\begin{array}{l}\text { PSL } \\
\text { (DLR, Berlin) }\end{array}$ & $50 \times 50 \times 40 \mathrm{~cm}$ & 1 bar & $700^{\circ} \mathrm{C}$ & Air and $\mathrm{N}_{2}$ & $\begin{array}{l}\text { Emissivity } \\
\text { measurement for } \\
\text { Venus atmospheric } \\
\text { windows at } 1 \mu \mathrm{m} ; \\
\text { External window for } \\
\text { NIR to FIR; } \\
\text { Monitoring Webcam }\end{array}$ \\
\hline $\begin{array}{l}\text { AVEC (JHU } \\
\text { APL) }\end{array}$ & $\begin{array}{l}\text { 2.5" diameter, } \\
\text { 9" depth, } 700 \\
\mathrm{~mL} \text { vol. }\end{array}$ & 95 bars & $470{ }^{\circ} \mathrm{C}$ & $\begin{array}{l}\mathrm{CO}_{2}, \mathrm{~N}_{2}, \mathrm{H}_{2} \mathrm{O} \\
\mathrm{CO}, \mathrm{HCl}, \\
\text { eventually } \\
\mathrm{SO}_{2}, \mathrm{OCS}, \mathrm{HF}\end{array}$ & $\begin{array}{l}\text { 2-4 wire feedthrough } \\
\text { capability; Duration } \\
\text { hours to days } \\
\text { (weeks); <1 week } \\
\text { turnaround }\end{array}$ \\
\hline $\begin{array}{l}\text { Large Venus } \\
\text { Test Chamber } \\
\text { (JPL) }\end{array}$ & $\begin{array}{l}31 \mathrm{~cm} \\
\text { diameter, } 2.4 \\
\text { m long }\end{array}$ & 92 bars & $460^{\circ} \mathrm{C}$ & $\mathrm{CO}_{2}$ & Feedthroughs \\
\hline $\begin{array}{l}\text { Small Venus } \\
\text { Test Chamber } \\
\text { (JPL) }\end{array}$ & $\begin{array}{l}10 \mathrm{~cm} \\
\text { diameter, } 1.6 \\
\mathrm{~m} \text { long }\end{array}$ & 92 bars & $460^{\circ} \mathrm{C}$ & $\mathrm{CO}_{2}$ & $\begin{array}{l}\text { Optional window for } \\
\text { optical experiments; } \\
\text { Externally located } \\
\text { plumbing hardware } \\
\text { for pneumatic sample } \\
\text { transfer experiments }\end{array}$ \\
\hline $\begin{array}{l}\text { Venus } \\
\text { Materials Test } \\
\text { Facility } \\
\text { (JPL) }\end{array}$ & $\begin{array}{l}18 \mathrm{~cm} \\
\text { diameter, } 56 \\
\mathrm{~cm} \text { tall }\end{array}$ & 92 bars & $460^{\circ} \mathrm{C}$ & $\mathrm{CO}_{2}$ & Feedthroughs \\
\hline $\begin{array}{l}\text { Venus } \\
\text { Weathering } \\
\text { Chamber } \\
\text { (JPL) }\end{array}$ & $\begin{array}{l}1.5 \mathrm{~cm} \\
\text { diameter, } 15 \\
\mathrm{~cm} \text { long }\end{array}$ & 1000 bars & $1000^{\circ} \mathrm{C}$ & $\mathrm{CO}_{2}, \mathrm{~N}_{2}, \mathrm{SO}_{2}$ & \\
\hline $\begin{array}{l}\text { High-pressure } \\
\text { wind tunnel* } \\
\text { (NASA ARC) }\end{array}$ & $\begin{array}{l}\text { Chamber: } 6 \mathrm{x} \\
2.3 \mathrm{~m} \text {. } \\
\text { Test section: } \\
20 \times 122 \mathrm{~cm}\end{array}$ & 20 bars & Ambient & $\begin{array}{l}\text { Air }\left(\mathrm{CO}_{2}\right. \\
\text { possible) }\end{array}$ & $\begin{array}{l}\text { Provides physical } \\
\text { simulation of aeolian } \\
\text { sand transport }\end{array}$ \\
\hline $\begin{array}{l}\text { GEER (NASA } \\
\text { GRC) }\end{array}$ & $\begin{array}{l}\text { 3' diameter } \mathrm{x} \\
\text { 4' length; } 800 \\
\text { L volume }\end{array}$ & 94 bars & $500{ }^{\circ} \mathrm{C}$ & $\begin{array}{l}\mathrm{CO}_{2}, \mathrm{~N}_{2}, \mathrm{SO}_{2} \\
\mathrm{CO}, \mathrm{OCS} \\
\mathrm{H}_{2} \mathrm{~S}, \mathrm{HCl}, \mathrm{HF} \\
\mathrm{H}_{2} \mathrm{O}\end{array}$ & $\begin{array}{l}\text { Feedthrough } \\
\text { capabilities; Long } \\
\text { duration experiments }\end{array}$ \\
\hline $\begin{array}{l}\text { Aabspec cell } \\
\text { (NASA } \\
\text { GSFC) }\end{array}$ & $6 " x 3 "$ & 138 bar & $950^{\circ} \mathrm{C}$ & $\mathrm{CO}_{2}, \mathrm{~N}_{2}, \mathrm{SO}_{2}$ & $\begin{array}{l}\text { High temperature and } \\
\text { pressure cell for IR } \\
\text { spectroscopy }\end{array}$ \\
\hline
\end{tabular}




\begin{tabular}{|l|l|l|l|l|l|}
\hline $\begin{array}{l}\text { Small Venus } \\
\text { Chamber } \\
\text { (NASA } \\
\text { GSFC) }\end{array}$ & $\begin{array}{l}\text { Chamber: 2.5” } \\
\text { diameter x 4" } \\
\text { depth } \\
\text { Volume: } 300 \\
\text { mL }\end{array}$ & 138 bar & $500^{\circ} \mathrm{C}$ & $\begin{array}{l}\mathrm{CO}_{2}, \mathrm{~N}_{2}, \mathrm{SO}_{2}, \\
\mathrm{CO}, \mathrm{OCS}, \\
\mathrm{H}_{2} \mathrm{~S}, \mathrm{HCl}, \\
\mathrm{H}_{2} \mathrm{O}\end{array}$ & $\begin{array}{l}\text { Optional window for } \\
\text { optical experiments }\end{array}$ \\
\hline $\begin{array}{l}\text { VICI (NASA } \\
\text { GSFC) }\end{array}$ & $\begin{array}{l}5 \text { in diam x 11 } \\
\text { in depth }\end{array}$ & 96 bar & $470{ }^{\circ} \mathrm{C}$ & $\mathrm{CO}_{2}, \mathrm{~N}_{2}, \mathrm{SO}_{2}$, & Feedthroughs \\
\hline $\begin{array}{l}\text { Cassiopeia } \\
\text { Chamber (U } \\
\text { Ark) }\end{array}$ & $\begin{array}{l}\text { Diameter: 2.5” } \\
\text { Depth: 6.63" } \\
\text { Volume: } \\
500 \mathrm{~mL}\end{array}$ & 206 bar & $510^{\circ} \mathrm{C}$ & $\begin{array}{l}\mathrm{CO}_{2} \\
\mathrm{CO}_{2} / \mathrm{SO}_{2} \\
\mathrm{CO}_{2} / \mathrm{COS}\end{array}$ & $\begin{array}{l}\text { Sapphire window; } \\
\text { Electrical } \\
\text { feedthrough; } \\
\text { Thermowell can be } \\
\text { used to attach } \\
\text { equipment, samples, } \\
\text { etc. }\end{array}$ \\
\hline
\end{tabular}

weathering rates. Smaller facilities like the APL Environment Chamber (AVEC) enable fast turnaround atmosphere-surface gas-solid reaction chemistry experiments [30], opening new avenues of study into reaction rates as short duration experiments are often less efficient in large test chambers. Some Venus chambers have begun to be used for investigating gas-gas phenomena [e.g., 31], but continued development of analytics in these chambers and chamber design to better accommodate gas phase chemistry are needed. The simulation of physical processes on Venus by facilities such as the high-pressure chamber at the NASA Ames Research Center that enables simulation of aeolian sand transport [29] are also important, as we understand from planets like Earth and Mars that geological processes and habitability are influenced by physical environments. The physical processes of such transport can be studied and parameterized for comparison to aeolian processes on other bodies [e.g., 28, 32].

Highlights of achievements made possible by facilities. Several milestones relating to technology and science have been realized due to the use of Venus experimental facilities. Unprotected electronics were demonstrated to function for 21 and 60 days at Venus surface conditions in the GEER facility [5,6], a major step in expanding the capability and duration of future Venus surface exploration. Multiple studies have examined long duration material stability at Venus surface conditions to guide the design of Venus mission elements [e.g., 8, 9].

Long duration (80 day) mineral weathering experiments were conducted in GEER, demonstrating the capability to better extrapolate reaction rates into more realistic timescales [25]. The Venus chambers located at the University of Arkansas and at NASA Goddard were the first used to study the stability of high dielectric substances composed of bismuth, tellurium, mercury, and sulfur at highland conditions on Venus in an effort to determine the source of the high altitude radar anomaly $[24,26]$. The Venus Wind Tunnel provided data showing a sand transport mode that is different than on Earth [33].

These highlights demonstrate major steps forward in enabling Venus exploration and understanding of this key planet. It is also of note most of these highlights were achieved in the last decade. This indicates we are now poised to take full advantage of Venus facilities, and that these facilities represent a much needed and productive aspect of Venus exploration.

Facilities of the Future: There is no single path forward when considering how to develop Venus experimental facilities in the next decade. While the specific needs of the community are varied, importantly, the need for these facilities is great. What follows here are some observations of desirable facility capabilities based on the current state of Venus work, presented in an effort to 
motivate developments that result in a strong fleet of Venus facilities that are capable of enabling VEXAG's desired Decade of Venus.

In-situ access. Most Venus chambers are constructed of opaque metals with as few intrusions as possible, as this makes them cheaper, safer, and easier to construct. The consequence of this is that it is difficult to monitor processes occurring inside the chambers during experiments. This limitation is workable for many situations, however further advances in Venus science and technology will greatly benefit from in-situ monitoring capabilities.

There are several kinds of in-situ monitoring that could take place. An important area is insitu gas chemistry monitoring, which is related to gas chemistry control, discussed below. This capability enables further atmospheric chemistry experiments, and benefits other types of experiments that need to track gas phase reactants and products, such as weathering experiments. Technology developments for missions, such as gas measuring instruments, also benefit from this monitoring as it provides a comparative measurement for the instrument during testing. This capability also guarantees that the experimental environment matches the desired environment. Visual or spectroscopic observations can also be useful in certain tests or experiments. For example, visual inspection could be used to monitor moving parts, identify failure times for structural components, or characterize other mission system components. Visual and spectroscopic observations of reacting solids could also benefit reaction rate studies. Depending on the facility, the shutdown procedure may result in the alteration of the sample, thus in-situ analysis can also be used to determine with certainty the solid phases present during the experiment.

All of these capabilities depend on an access point to the inside of a chamber, whether it be an observation port or insertion of a sensor or detector through a feedthrough. Many current Venus facilities have some level of feedthrough capability, but providing the above mentioned techniques requires development in this area. Interestingly, enhancing in-situ access into Venus chambers is the same type of problem as enhancing access to Venus itself from inside protected pressure vessels on mission assets. These areas of development likely will feed into each other, and represent synergistic regions of Venus exploration. Once in-situ access is further developed, it will allow for more complex science investigations to take place in these experimental facilities.

Gas chemistry control. Precise control of gas chemistry during science experiments, and in several cases for technology demonstrations, is a necessary capability. This capability is dependent on an accurate gas monitoring system for the facility. Some materials used to construct experimental facilities are not stable in the simulated near surface environment of Venus [e.g., 8], and their reactions with the simulated Venus atmosphere drive the gas composition away from the intended composition, thus requiring a method to maintain the desired gas chemistry. There are several possible ways to mitigate this problem, and specific solutions will be needed for each facility. The choice of chamber materials can greatly help in this issue, as using less reactive materials will avoid this problem. Some other possible strategies could include a gas flow through system or gas boosting during the experiment, both solutions that are related to the facility's gas control system.

Test chamber capacity. Currently, Venus facilities support a variety of sample volumes through varied chamber sizes. Larger chambers are needed to accommodate testing and development of larger mission hardware. Extensive testing of landed surface mission components at Venus surface conditions are needed to ensure that any such future mission can survive for extended periods of time on the surface, and may require development of even larger chambers than are operating currently. However, small chambers are more ideal for many other kinds of 
studies, such as mineral weathering experiments. Thus, it is important to maintain and develop a variety of chamber sizes.

Community facility access. Access to Venus test facilities, both in test time and affordability for a wide range of interested users, is central to ensuring the momentum gained in recent years around Venus experimentation can continue. It must be recognized that in order to sustain timely Venus experimental programs, multiple facilities must be available to the community in order to accommodate the long test times often required for many experiments. Visibility of facilities and community connectedness are also critical to keep our momentum.

Conclusions: The importance of Venus experimental facilities is demonstrated by the science and technical advancements they have recently enabled. These facilities play a key role in our exploration of Venus, and drive several key stages of the exploration cycle. Testing of mission components, technologies, and instrumentation under Venus conditions is needed to ensure survivability and proper functionality; this can also enable us to develop ways to make Venus exploration less time limited, more extensive, and more mobile, as on other planets. Experiments based on past and future mission data can be used to test our interpretations and explanations of those data, and better describe and understand the natural phenomena that shape our neighboring world. The Venus community needs these facilities to continue to operate, and to progress along with their evolving needs.

\section{References:}

[1] Greeley, R., et al. JGR: Planets, 1992. 97(E8): p. 13319-13345. [2] Weitz, C.M., et al. Icarus, 1994. 112(1): p. 282-295. [3] Hunter, G. et al. Venus Technology Plan. 2019. https://www.lpi.usra.edu/vexag/reports/VEXAG_Venus_Techplan_Current.pdf. [4] Lodders, K. and B. Fegley, The planetary scientist's companion. 1998: Oxford University Press. [5] Neudeck, P.G., et al. IEEE Journal of the Electron Devices Society, 2018. 7: p. 100-110. [6] Neudeck, P.G., et al. AIP Advances, 2016. 6(12): p. 125119. [7] Marcq, E., et al. Space Sci Revs, 2018. 214(1): p. 10. [8] Costa, G.C., et al. Corrosion Sci, 2018. 132: p. 260-271. [9] Lukco, D., et al. Earth and Space Sci, 2018. 5(7): p. 270-284. [10] O'Rourke, J. and A. Treiman et al. Venus Goals, Objectives, and Investigations. 2019. https://www.lpi.usra.edu/vexag/reports/VEXAG_Venus_GOI_ Current.pdf. [11] Dyar, M., et al. 15th VEXAG, 2017. Abstract \#8004. [12] Helbert, J., et al. Infrared Remote Sensing and Instrumentation XXIV, 2016. Abstract \#9973. [13] Helbert, J., et al. 15 $5^{\text {th }}$ VEXAG, 2017. Abstract \#8006. [14] Helbert, J., et al. Infrared Remote Sensing and Instrumentation XXVII, 2018. p. 107650D. [15] Lambert, J., et al. 41 ${ }^{\text {st }}$ LPSC, 2010. Abstract \#2608. [16] Kremic, T., G. Hunter, and J. Rock, 15th VEXAG, 2017. Abstract \#8035. [17] Fegley Jr, B., et al. Icarus, 1995. 115(1): p. 159-180. [18] Johnson, N.M. and B. Fegley Jr, Icarus, 2003. 164(2): p. 317-333. [19] Johnson, N.M. and B. Fegley Jr, Icarus, 2000. 146(1): p. 301-306. [20] Hong, Y. and B. Fegley Jr, Berichte der Bunsengesellschaft für physikalische Chemie, 1997. 101(12): p. 1870-1881. [21] Treiman, A. and B. Fegley Jr. 22nd LPSC, 1991. p. 1409. [22] Straub, D.W. 24 ${ }^{\text {th }}$ LPSC, 1993. p. 1367-1368. [23] Berger, G., et al. Icarus, 2019. 329: p. 8-23. [24] Kohler, E., University of Arkansas, 2016. [25] Radoman-Shaw, B.G., Case Western Reserve University, 2019. [26] Port, S., V. Chevrier, and E. Kohler, Icarus, 2020. 336: p. 113432. [27] Greeley, R., et

al. Icarus, 1984. 57(1): p. 112-124. [28] Burr, D.M., et al. Nature, 2015. 517(7532): p. 60. [29] Burr, D.M., et al. Aeolian Research, 2015. 18: p. 205-214. [30] Lessis, M., N. Izenberg, and R. Osiander, 50 ${ }^{\text {th }}$ LPSC, 2019. Abstract \#1084. [31] Lebonnois, S., et al. Icarus, 2018. 338: 113550. [32] Kok, J.F., et al. Rep on progress in Physics, 2012. 75(10): p. 106901. [33] Greeley, R. and J.R. Marshall, Nature, 1985. 313(6005): p. 771. 